\title{
International Trade and Unemployment in Less Developed Countries
}

\author{
Fernando Mesa \\ Department of Economics, University of Rosario, Bogotá, Colombia \\ Email: fmesaparra@gmail.com, fernandog.mesa@urosario.edu.co
}

Received September 27, 2012; revised October 28, 2012; accepted November 29, 2012

\begin{abstract}
The main interest focus of this paper is the relation between international trade and the labour market, with an emphasis on the unemployment rate, and the allocation of workers among sectors. A general trade equilibrium model with three sectors is constructed for a less developed country. An informal and un-tradable sector is characterised by flexible wages, while the other two sectors are tradable, export and import sectors. The model imposes a binding minimum wage on unskilled labour and wage distortions on skilled labour. Comparative statics are used to analyse the effects on the labour market of an open economy, a rise in the minimum wage and a positive productivity shock in the export sector.
\end{abstract}

Keywords: Trade Reforms; Trade and Labor Markets Interactions; Demand for Labor

\section{Introduction}

Open economic policy in less developed countries (LDC) leads to consideration of the main effects on the labour market, a relevant analysis because of labour's impact on economic efficiency and social welfare. Outside the economics profession, many people think that trade agreements lead to the destruction of jobs and significant unemployment. Although this negative effect on employment is to be expected initially, international trade can also bring about the creation of jobs as a result of a new economic dynamic.

The main contribution of the present study is the construction of a general trade equilibrium model for a LDC to explain the effect on unemployment and the allocation of workers among sectors when the custom barriers are removed, or even when free trade agreements are signed. It is important to notice that LDCs are defined in this paper in two senses. Firstly, they are countries where the presence of sectors with enormous productivity differenttials are persistent, such as this economic phenomenon is well-known in the economic literature and identified as the technological and institutional dualism. Secondly, it is also defined when the market adjustments are imperfect, and it is dominated by market frictions and institutional restrictions.

The model deals with four issues observed in LDCs and embodied in two tradable export and import sectors, and a third un-tradable sector. The two tradable sectors demand both skilled and unskilled workers, the third only unskilled workers. The economy is characterised by the following: 1) The mobility of skilled workers in the export and import sectors is imperfect, and workers earn different wages; 2) the unskilled labour market is segmented between formal and informal sectors; 3) unskilled workers in the formal sector are paid a minimum wage fixed by the government; and 4) the third sector, informal and un-tradable, is characterised by flexible wages and require only unskilled workers. These important features considered simultaneously have not been taken into account previously by the theoretical literature.

Recently, several international labour models have taken into consideration the effects of sticky wages and imperfect labour mobility on unemployment. For example, Davis [1] developed a model of trade and the labour market involving two countries. One country is a stylized characterisation of flexible-wage markets while the other represents an economy with a rigid labour price as a consequence of fixing a minimum wage. Davis finds that the first country sees an increase in inequality between high and low wages, while the second experiences a dramatic increase in unemployment.

Imperfect mobility of skilled workers between the export and import sectors is explained in this paper by turnover costs associated with hiring and training. In general, newly hired workers do not have the same skill as the outgoing workers they replace. That issue is discussed widely by Stiglitz [2] who introduces turnover costs under the concept of efficiency wage theory, which 
suggests that higher wages can result in higher productivity levels. When wages are above the market-clearing level for efficiency reasons, the unemployment rate rises in an equilibrium state [3].

The proposed model also considers some mobility restrictions on the unskilled worker between tradable and un-tradable sectors. It is assumed that unskilled people would prefer to be employed in the tradable sector rather than in the un-tradable sector because of its higher wage rate and better working conditions. The direct implication of these conditions is that unskilled people allocated in the tradable and un-tradable sectors exhibit some imperfect mobility, which is measured by the elasticity of labour mobility, suggested in the pioneering work of Casas [4]. Casas introduces imperfect labour mobility in a standard two-sector, two-factor general equilibrium model. As in the Casas model [4], the elasticity of labour mobility is introduced here by a parameter that addresses this issue.

The model constructed here the unskilled workers employed in the organized tradable sectors receive a relatively high contractual minimum wage, while their counterparts in the un-tradable sector earn a lower competetive wage. With two different rates of pay earned by unskilled people in two different segments of the labour market, the model includes an unemployment rate attributed to both imperfect labour mobility and a sector-specific sticky wage. Some authors, like Parai and Beladi [5], explain unemployment rates through the manufacturing sticky wages, of the Harris-Todaro variety. Wei and Yabuuchi [6] additionally examine the implications of wage subsidy policy and factor production growth on the rate of unemployment, also using the Harris-Todaro model. Both of these treatments are characterised by imperfect labour mobility and urban unemployment ${ }^{1}$.

There is solid theoretical evidence that free trade in LDC produces unemployment when prices of imported goods fall. However, employment gains in the expanding export sector might offset this. This effect will be stronger if the structural change also produces an increase in productivity. Several studies have shown that higher productivity is strongly correlated with the export status [9]. This feature plays an important role in the results that is obtained in the suggested model.

Empirical research has documented both imperfect inter-sector labour mobility and wage differentials. Imperfect labour market adjustment cannot be explained only by observable differences in worker or job characteristics that might require different compensations. Fajnzylber and Maloney [10] show that periods of openness to trade in Colombia and Chile present higher labour demand elasticity, while some evidence in Mexico links trade

${ }^{1}$ The consequences of economic liberalisation policies on the skilledunskilled wage inequality in LDC are analysed theoretically by Marjit [7] and Chaudhuro and Yabuuchi [8]. liberalisation with reductions in some worker's demand elasticity and the worsening of wage inequality. Goldberg and Pavenick [11] show that trade liberalisation in Colombia was associated with increased productivity but also with wages differentials for the same type of workers. Bosh et al. [12] show that 35 to 60 percent of Latin American workers are found in the informal sector as a consequence of labour market distortions resulting from a set a minimum wage and other institutional restrictions in the formal sector. Goldberg and Pavcnick [13] find a weak relationship between variation in protection across time and the share of informality in Brazil and Colombia. Esquivel and Rodríguez-López [14] analysed the Mexican experience before and after NAFTA (the North Free Trade Agreement) and shows how trade liberalisation and skill-biased technological change explain wage inequality in Mexico.

This study's main findings are as follows: 1) Free trade policies in a small open LDC could explain some unemployment levels if the market frictions and institutional restrictions are considered; 2) the unemployment effects might be offset if the trade liberalisation improves both the efficient allocation of resources in the economy and productivity in the export sector; 3) improved export performance in the economy might increase the un-tradable sector and decrease the unemployment rate; so that more productive firms are bigger, earn higher profits and demand more workers; and 4) the positive effects on employment from the growing export sector will be reduced if the minimum wage is raised.

The remainder of the paper is organized as follows. The next section presents the basic model. Section 3 contains analyses of the comparative statics when the economy is liberalised. Section 4 considers the negative impacts when the minimum wage is increased and the positive effect of increased productivity in the export sector. The last section concludes.

\section{Model Framework}

This section is divided in two folds. The first is dedicated to explain mainly the basic model, and the second fold is devoted to discuss especial features that characterise the unskilled labour market, both in the formal and informal markets.

Let us first define three sectors by analytical convenience: two tradable export and import sectors, and one un-tradable sector. Outputs are $x, y$, and $n$, respectively, such that $x$ and $y$ are produced with skilled and unskilled workers $\left(L_{i}\right.$, and $L_{u i}$, where $\left.I=x, y\right)$ under constant returns to scale technology. The un-tradable sector $(n)$ demands only unskilled workers $\left(L_{n}\right)$.

The model is of a static labour market. Its equilibrium is the state toward which the market tends and where, 
once arrived, it will remain. That equilibrium will not be labour-market-clearing. My purpose is to analyse the equilibrium positions and their interaction owing to their link via trade. I will not analyse the dynamics by which these equilibriums are reached.

Only the production side of the economic system is described, and then the first-order conditions are derived. A reduced form is obtained in order to analyse the comparative statics (see Appendixes 1 and 2). The results explain changes in the employment level of skilled and unskilled workers, and also changes in the unemployment rate, when a LDC has applied a trade policy designed to open its economy.

\subsection{Basic Equations}

There are six basic equations. Three profit sector equations describe the behaviour of the two tradable sectors and the one un-tradable sector; two equations balance skilled and unskilled workers, and one equation explains the imperfect unskilled labour mobility between the tradable and un-tradable sectors.

Firms wish to maximise their profits and to do this they must minimise their labour costs. This means that they hire workers, increase wages, and improve worker quality when it is in their profit-maximising interest to do so. Firms in the tradable sectors pay higher wages to skilled workers if these wages increase labour productivity [2]. This is the efficiency wage theory, that explains how higher wages can result in higher productivity [3].

Sector outputs are obtained according to the CobbDouglas functions. In addition, there is an assumption that the export sector utilises skilled labour more intensively than the import sector. The two profit equations for the tradable sectors are written as follows. For the export profit sector $(x)$

$$
\begin{aligned}
\pi_{x}= & (1+S)^{-1} L_{x}^{\beta} L_{u x}^{1-\beta} \\
& -\left(r L_{x}+\bar{W} L_{u x}\right)\left[1+\alpha\left(1+S_{y}\right)\right](1+h)^{-1}-C,
\end{aligned}
$$

and for the import profit sector $(y)$

$$
\pi_{y}=\left(1+S_{y}\right) L_{y}^{\beta_{y}} L_{u y}^{1-\beta_{y}}-r_{y} L_{y}-\bar{W} L_{u y}-C_{y} .
$$

The export price is affected negatively by $(1+S)$, and the import price positively by $\left(1+S_{y}\right)^{2}$. $S$ is the external restriction parameter for exports and $S_{y}$ is the protected parameter for imports given by domestic tariffs.

The first term at the right hand in Equations (1) and (2) are the output values obtained through the Cobb-Douglas production functions. The labour costs, $r$ and $r_{y}$, are the skilled labour wages, and $\bar{W}$, is the minimum wage

${ }^{2}$ By assumption prices of exports and imports are equal to 1 . fixed by the government and paid to unskilled workers employed in the tradable sectors.

A percentage index of technological progress is indicated by $h$ in Equation (1). For the sake of simplicity, higher productivity drives a lower marginal cost for export goods. Thus, total labour cost is divided by $(1+h)$, bigger than 1 , so that firms decide how many people to employ at any given point of time. The imported component for the export sector is introduced by the parameter $\alpha$, whose value is less than 1 .

The last terms $\left(C\right.$ and $\left.C_{y}\right)$ in Equations (1) and (2) are the training-hiring costs and are functions of the rate of employee turnover. They are stated as

$$
C=\frac{\bar{W}^{2}}{r} L_{x}^{b}, C_{y}=\frac{\bar{W}^{2}}{r_{y}} L_{y}^{b_{y}} .
$$

The turnover costs for skilled labour, or the average tenure period, is a decreasing function of the wage paid to the skilled workers ( $r$ and $r_{y}$ ) and an increasing function with respect to the minimum wage rate $(\bar{W})$. They play a dominant role in explaining the skilled unemployment rate in the tradable labour market [2].

Parameters $\beta$ and $\beta_{y}$ are the proportion of skilled workers in the production functions, while the parameters $b$ and $b_{y}$ capture part of the turnover cost for skilled workers. The feasible parameter values are defined as follows:

$$
0 \leq \beta_{y}<\beta \leq 1 ;(b-1),\left(b_{y}-1\right)>1 ; \text { and } 0<\alpha<1 .
$$

The third sector is un-tradable and demands only unskilled workers. It is characterised by flexible wages, set by a number of small businesses, which prospective workers enter only as a last resort ${ }^{3}$. This is a subsistence sector and the minimum wage paid to people hired by the tradable-formal sector sets its maximum wage level. The un-tradable sector's profit function is written as:

$$
\pi_{n}=f\left(L_{n}\right)-W_{n} L_{n} ; \text { where } f^{\prime}\left(L_{n}\right)>0 \text { and } f^{\prime \prime}\left(L_{n}\right)<0 \text {. }
$$

Unskilled workers $\left(L_{n}\right)$ allocated to the un-tradable sector display positive but diminishing marginal productivity. Thus, people hired in this sector are paid by their marginal productivity $\left(W_{n}=f^{\prime}\left(L_{n}\right)\right)$.

The proportions of skilled and unskilled workers are given by the following identities. The skilled labour market balance is

$$
\bar{L}=L_{x}+L_{y}+L_{d},
$$

and the unskilled labour market balance is

$$
\bar{L}_{u}=L_{u x}+L_{u y}+L_{n}+L_{u d} \text {. }
$$

$\overline{{ }^{3} \text { Marjit [7] considers that households working in informal activities and }}$ other people without jobs are unemployed unskilled people. 
Let $\bar{L}$ and $\bar{L}_{u}$ be the endowments of skilled and unskilled workers, respectively. Skilled and unskilled people who are unemployed are represented by $L_{d}$ and $L_{u d}$, respectively.

\subsection{Unskilled Labour Market}

The tradable sectors offer relatively attractive wages alongside other favourable conditions for unskilled workers, while the un-tradable sector, consisting of small firms, some of which are engaged in informal economic activity, offers relatively unattractive wages and conditions ${ }^{4}$. For that reason, reallocation of employment from a tradable to an un-tradable sector can be considered undesirable. The un-tradable sector is defined by free entry and competitive markets, unregulated activity, and skills acquired outside the formal school system.

It is therefore assumed that unskilled workers do not move freely between the tradable and un-tradable sectors. This imperfect mobility is described by the elasticity of inter-sector labour mobility, as introduced by Casas [4]. The assumption is that whatever the initial wage differential between the two sectors, a change in the wage ratio is required to induce movement of workers in either direction. However, this movement will not continue indefinitely. Once a new allocation of workers and that constitutes the equilibrium is reached, that new state will be stable even though it involves different wages between both sectors.

The equation of imperfect unskilled labour mobility is written as

$$
\frac{\bar{W}}{f^{\prime}\left(L_{n}\right)}=\left(\frac{L_{u x}+L_{u y}}{L_{n}}\right)^{\frac{1}{\lambda}} ; \lambda>0,
$$

where $\lambda$ is the elasticity of labour mobility, and is assumed to be constant ${ }^{5}$. Labour is completely immobile if $\lambda=0$, and mobility is perfect if $\lambda=\infty$. The previous equation is rewritten as

$$
\frac{L_{u x}+L_{u y}}{L_{n}}=\left(\frac{\bar{W}}{f^{\prime}\left(L_{n}\right)}\right)^{\lambda} .
$$

A fixed minimum wage $\bar{W}$ is paid to unskilled workers employed by the tradable sectors, and that wage is higher than the wage earned in the un-tradable sector.

\footnotetext{
${ }^{4}$ An opposite view is that the informal economy is a desirable sector that workers could choose in preference to a formal sector. This internal dualism combines two opposite characterisations. Fields [3] offers a summary of reasons why workers might prefer working in the informal sector. Among other reasons they could earn more, or at least hope to earn more; also, they value self-employment and the relative independence.

${ }^{5}$ Casas [4] derives this type of labour supply from a CES utility function.
}

That is

$$
\bar{W}>f^{\prime}\left(L_{n}\right) .
$$

The inter-sector wage differential explains why some unskilled workers are unemployed $\left(L_{u d}\right)$. This outcome would not come about if all jobless workers could migrate again into the un-tradable sector and economy activity.

When the wage gap between the tradable and untradable sectors is higher, more unskilled workers will stay in the tradable sector. In fact, more unskilled workers migrate than there are vacancies and this explains why some unskilled workers could be unemployed. The unemployment level acts to discourage further labour movements. As long as the wage gap is increased, the unemployment equilibrium rate will be greater.

\section{Comparative Static Analysis}

The starting point of this section offers concise details about the procedure to make a fairly tractable analysis of the comparative static of the model. The order of this Comparative static enquiry is presented according to the course that LDCs face up when custom barriers are removed. The first issue is to analyse the effects that trade liberalisation produce in the economy, if tariff and external restrictions are minimised. Institutional restrictions imposed on the labour market are studied afterwards, and they are handled through an increase in the minimum wage fixed by the government. Finally, a positive shock on the export sector is introduced, since this effect should be expected as consequence of new competitive conditions.

Seven first-order conditions with respect to skilled and unskilled labour demands, and the skilled wages are derived from Equations (1) and (2). Comparative-static analysis is derived from the previous conditions (see Appendixes 1 and 2). Three cases are studied when there are changes in the parameters related to the trade policy, minimum wage, and export productivity.

\subsection{Reduced Model}

The seven first-order conditions (see Appendix 1), the two labour balances-Equations (4) and (5) - and the mobility restrictions for unskilled labour-Equation (6) set up the ten equilibrium conditions of the model. They allow us to derive the following results: Three factor production prices $\left(r, r_{y}, W_{n}\right)$, five levels of demand for workers $\left(L_{x}, L_{y}, L_{n}, L_{u x}, L_{u y}\right)$ and the unemployment levels of unskilled and skilled workers $\left(L_{d}, L_{u d}\right)$.

Skilled labour wages are derived from Equations (35) and (38), and they are 


$$
\begin{gathered}
r=\left(\frac{1+h}{1+\alpha\left(1+S_{y}\right)}\right)^{2} \bar{W} L_{x}^{\frac{b-1}{2}}, \\
r_{y}=\bar{W} L_{y}^{\frac{b_{y}-1}{2}},
\end{gathered}
$$

such that wages for skilled worker are positively related to both the minimum wage rate $(\bar{W})$ and training-hiring costs per worker. In the case of the export sector-Equation (7) - the skilled worker wage is negatively related to the protected parameter for imports, $S_{y}$, and positively related to the productivity level, $(1+h)$.

Equations (7) and (8) are replaced in the first order conditions. Then, those conditions are differentiated with respect to labour demands, trade policy parameters, the minimum wage, and technology changes (see Appendix 2 ), and a equation system is obtained and written in matrix form as

$$
H \cdot \mathrm{d} L=A \cdot \mathrm{d} D,
$$

where $\boldsymbol{H}$ is the coefficient matrix; $\mathbf{d} \boldsymbol{L}$ is a vector of labour variations and writen in transpose form is $\left(\begin{array}{llll}\mathrm{d} L_{x} & \mathrm{~d} L_{u x} & \mathrm{~d} L_{d} & \mathrm{~d} L_{n}\end{array}\right) . \boldsymbol{A}$ is a vector of parameters that premultiply the vector $\mathbf{d} \boldsymbol{D}$. The last vector in transpose form is defined as $\left(\begin{array}{llll}\mathrm{d} S & \mathrm{~d} S_{y} & \mathrm{~d} W & \mathrm{~d} h\end{array}\right)$.

\subsection{Trade Policy Liberalisation}

Two trade policy effects on the labour market are considered. The first occurs when the trade policy is fixed by foreign countries and has a negative impact on domestic exports, $(1+S)$. The second occurs when trade policy is fixed by a LDC in order to restrict its own imports, $\left(1+S_{y}\right)$. Both policies are oriented toward reducing international trade flows.

In recent decades, restrictions on trade flows have been substantially reduced in most countries, and the dispersion of protection across products and sectors has been minimised. These processes of reform have hit the import sector as the former protection barriers had allowed many inefficient firms to continue to produce and to undertake few productivity upgrades.

Nowadays countries design their trade policies to liberalise the international markets. The more important trade policies are currently related to bilateral, regional, and multilateral trade agreements that restrict the capacity of countries to change their trade policies. As a matter of fact, they have made a commitment to be involved in the process of globalization and to move their economies toward an integrated world.

International trade restrictions induced by foreign countries, $(1+S)$.

If foreign countries remove trade restrictions, domestic firms might raise their own export prices in the inter- national market. The effects are given only in the export sector. Less restriction induced by foreign countries conducts to increase the skilled demand in the export sector and reduce the unemployment rate. These results are presented in Equations (10). This foreign trade policy oriented to be less restrictive also impacts positively the unskilled workers both in the formal and informal sectors, as they are shown in Equation (11). This positive effect is reduced for skilled workers employed in the export sector by the turnover costs, $(b-1)$.

$$
\begin{gathered}
\frac{\mathrm{d} L_{x}}{\mathrm{~d} S}=-\frac{2 L_{x}}{\beta(1+S)(b-1)}<0 ; \frac{\mathrm{d} L_{y}}{\mathrm{~d} S}=0 ; \\
\text { and } \frac{\mathrm{d} L_{d}}{\mathrm{~d} S}=-\frac{\mathrm{d} L_{x}}{\mathrm{~d} S}>0 ; \\
\frac{\mathrm{d} L_{u x}}{\mathrm{~d} S}=-\frac{(b+1) L_{u x}}{\beta(1+S)(b-1)}<0 ; \frac{\mathrm{d} L_{u y}}{\mathrm{~d} S}=0 ; \\
\frac{\mathrm{d} L_{n}}{\mathrm{~d} S}=\frac{1}{\Theta} \cdot \frac{(b+1) L_{u x}}{\beta(1+S)(b-1)}<0 .
\end{gathered}
$$

The parameter $\Theta$ is defined as (see Appendix 2)

$$
\Theta=\left(\frac{\bar{W}}{f^{\prime}\left(L_{n}\right)}\right)^{\lambda}\left[\lambda \frac{f^{\prime \prime}\left(L_{n}\right)}{f^{\prime}\left(L_{n}\right)} L_{n}-1\right]<-1,
$$

and it is a decreasing function of the elasticity labour mobility $(\lambda)$.

Reducing external trade restrictions on exports allows domestic firms to become more competitive in external markets. Policy liberalisation in favour of exports produces two meaningful results. First, the export sector increases its demands for skilled and unskilled workers (labour demand in the import sector is not affected); and second, as long as the export sector gets larger, wages paid for skilled workers go up (Equations 7 and 8), and there is a general reduction of the unemployment rate in the economy as a whole.

Equation (13) is obtained with the results in Equation (11) and shows a reduction of unemployment in the unskilled labour market when the external restrictions are removed.

$$
\frac{\mathrm{d} L_{u d}}{\mathrm{~d} S}=\frac{(\Theta-1)}{\Theta} \cdot \frac{(b+1) L_{u x}}{\beta(1+S)(b-1)}>0 .
$$

Cutting the domestic tariff, $\left(1+S_{y}\right)$.

As the economy is opened to external competition, many firms are restructured and stay in the market, but others have to close. When the domestic government cuts its tariffs, the impacts on the skilled labour force are evident in this model. Skilled worker employment in the export sector increases as this sector expands, as shown in Equation (14). By contrast, the import sector is depleted, and therefore demand for skilled workers in 
this sector falls (15). Moreover export skilled labour demand is soften by the turnover cost, $(b-1)$, and the domestic tariff, $\phi$; Equation (14). Clearly the less import costs affect negatively the skilled labour demand in the import sector, although this effect is reduced by the imperfect labour mobility, given by $\left(b_{y}-1\right)$; Equation (15).

$$
\begin{gathered}
\frac{\mathrm{d} L_{x}}{\mathrm{~d} S_{y}}=-\frac{(2-\beta) \alpha L_{x}}{\beta \phi(b-1)}<0, \\
\frac{\mathrm{d} L_{y}}{\mathrm{~d} S_{y}}=\frac{2\left(1-\beta_{y}\right) L_{y}}{\beta_{y}\left(1+S_{y}\right)\left(b_{y}-1\right)}>0,
\end{gathered}
$$

where $\phi=\left(1+\alpha\left(1+S_{y}\right)\right)>0$.

Two opposite forces affect the unemployment rate of skilled workers, as in Equation (16). These results are derived from Equations (14) and (15). On the one hand, there is a positive correlation between the trade policy liberalisation and the skilled labour demand in the export sector; thus, the unemployment rate tends to fall in this sector. On the other hand, there is an unfavourable effect on the import sector, and the unemployment rate in this sector tends to increase. The net effect depends on which sector is bigger. If the tradable import sector is bigger, the overall unemployment rate goes up; see Equation (16).

$$
\frac{\mathrm{d} L_{d}}{\mathrm{~d} S_{y}}=\frac{(2-\beta) \alpha L_{x}}{\beta \phi(b-1)}-\frac{2\left(1-\beta_{y}\right) L_{y}}{\beta_{y}\left(1+S_{y}\right)\left(b_{y}-1\right)} .
$$

However, both effects are reduced by the traininghiring costs, as given by $(b-1)$ for the export sector, and $\left(b_{y}-1\right)$ for the import sector. It is well known that job creation takes time, while job destruction can take place immediately. Therefore, there will be a higher overall unemployment rate if the import sector, where the price falls, is the dominant sector.

The impacts on unskilled workers are as follows. Since there is an imported component in production in the export sector $(\alpha)$, cutting tariffs leads to reduced demand for unskilled labour in this sector. This makes sense when firms in this sector can import intermediate goods at lower prices and substitute locally produced items for imported components. The friction labour mobility $(b)$ does not have a sharp tend to minimise the effect, but this is reduced if proportion of skilled workers $(\beta)$ is high; see Equation (17).

$$
\frac{\mathrm{d} L_{u x}}{\mathrm{~d} S_{y}}=\frac{(b+1-3 \beta) \alpha L_{u x}}{\beta \phi(b-1)}>0,
$$

Lower demand for unskilled labour in the export sector allows the tradable import sector and the untradable sector to increase their demands for these workers; see first terms on the right hand side in Equations (18) and (19). However, lower protective barriers affect these sectors negatively at the same time (second terms). The net effect on demand for unskilled labour with respect to the sectors will depend on which is dominant in the economy. If the tradable-import sector dominates $\left(L_{u y}\right)$, then a reduction of custom barriers negatively affects the demand for unskilled labour. In turn, a large migration of unskilled workers from the tradable sector to the un-tradable sector could explain lower productivity in the economy overall.

$$
\begin{aligned}
& \frac{\mathrm{d} L_{u y}}{\mathrm{~d} S_{y}}=-\frac{2(b+1-2 \beta) \alpha L_{u x}}{\beta \phi(b-1)}+\frac{\left(b_{y}+1\right) L_{u y}}{\beta_{y}\left(1+S_{y}\right)}, \\
& \frac{\mathrm{d} L_{n}}{\mathrm{~d} S_{y}}=\frac{1}{\Theta}\left\{\frac{(b+1-\beta) \alpha L_{u x}}{\beta \phi(b-1)}-\frac{\left(b_{y}+1\right) L_{u y}}{\beta_{y}\left(1+S_{y}\right)}\right\} .
\end{aligned}
$$

Since there are mobility restrictions on unskilled labour between the tradable and un-tradable sectors, given by the expression $\Theta$ in Equation (19), any effects from removing tariffs in the economy are dampened by the market frictions. This also applies to tradable import sector frictions through the term $\left(b_{y}+1\right)^{6}$.

Equation (20) is derived from Equations (17)-(19). The main implication from Equation (20) is that trade liberalisation increases the unemployment rate among unskilled workers, as long as the import sector is the largest in the economy $\left(L_{u y}\right)$. If acceptable economic opportunities are lacking in the un-tradable sector, where the market entry costs for firms are relatively low, some workers are forced to be unemployed. As long as the export sector is expanding $\left(L_{u y}\right)$, this negative effect can be reduced. It is worth saying that in this case mobility restrictions in Equation (20) for export sector are negligible $(b)$, but that restrictions do be significant for import sector, $\left(b_{y}+1\right)$.

$$
\frac{\mathrm{d} L_{u d}}{\mathrm{~d} S_{y}}=\frac{\Theta-1}{\Theta} \cdot\left[\frac{(b+1-\beta) \alpha L_{u x}}{\beta \phi(b-1)}-\frac{\left(b_{y}+1\right) L_{u y}}{\beta_{y}\left(1+S_{y}\right)}\right] .
$$

where $\frac{(\Theta-1)}{\Theta}>0$.

An additional implication is the inter-sector wage differential arising from imperfect labour mobility. Once a new allocation of the labour force is established, which constitutes a new stable equilibrium, it features different wage rates among workers in different sectors. International trade liberalisation leads to an increase in the wage gap between the skilled workers in the export and import sectors; see Equations (7) and (8). As long as the

${ }^{6}$ Those parameters are the skilled labour frictions but they indirectly affect the unskilled labour market through the production functions. 
share of the export sector goes up, the unskilled labour wage gap between the minimum wage and the wage paid in the un-tradable sector increases. This last outcome is attributable to the decreasing marginal productivity in the un-tradable sector.

The main theoretical results presented in this section can be summarized by noting that a process of international market liberalisation in an LDC produces the following effects on the unemployment rate and unskilled workers employed in the un-tradable sector:

1) The removal of international trade barriers (e.g., through free trade agreements) has two positive effects on the export sector that act to reduce unemployment among both skilled and unskilled workers. Conversely, it has a negative effect on the demand for both skilled and unskilled labour in the import sector. Additionally, these two opposite effects are reduced by the turnover cost, in the case of skilled workers, and by labour mobility restrictions, in the case of unskilled workers.

2) International trade policy liberalisation has a mixed effect on the un-tradable sector and on unemployment among unskilled workers. More competition in the import sector leads to reduced demand for labour in the un-tradable sector and, therefore, increased unemployment in the unskilled labour market. This effect is, however, offset by the labour adjustment in the export sector to some extent.

\section{Changing the Minimum Wage Policy and Augmenting Export Sector Productivity}

This section begins with a discussion of the effects that a change in the minimum wage has on the unemployment level for different types of workers. The model is then examined in terms of a boom in productivity attributable to free trade, especially for workers employed in the export sector ${ }^{7}$.

\subsection{Changing the Minimum Wage Rate Policy}

A critical issue related to free trade agreements is the effect that a minimum wage policy has on the labour market. Since a higher minimum wage raises pay for skilled workers-see Equations (7) and (8) - there is an unambiguously negative effect on demand for skilled labour. Higher wages drive up production cost, which erodes a country's comparative advantage and destroys jobs, as it is shown in Equations (21) and (22). Hence unemployment exists because the entire labour market is subject to an exogenously specific floor, or minimum, which exceeds the level required for full employment. However, the negative effect regarding skilled workers

${ }^{7}$ Currently, there are positive spill-over effects on the rest of the economy. may be reduced by the turnover cost, $(b-1)$ and $\left(b_{y}-1\right)$.

The results for the export and import sectors are

$$
\begin{gathered}
\frac{\mathrm{d} L_{x}}{\mathrm{~d} \bar{W}}=-\frac{2 L_{x}}{\beta(b-1) \bar{W}}<0, \\
\frac{\mathrm{d} L_{y}}{\mathrm{~d} \bar{W}}=-\frac{1}{\bar{W}} \cdot \frac{2\left(2-\beta_{y}\right) L_{y}}{\beta_{y}\left(b_{y}-1\right)}<0 .
\end{gathered}
$$

Equation (23) points out a positive relation between minimum wage $(\bar{W})$ and the unemployment of skilled workers. There is a positively relation to the skilled workers employed $\left(L_{x}\right.$ and $\left.L_{y}\right)$ and negatively to the turnover-cost, $(b-1)$ and $\left(b_{y}-1\right)$. Thus the unemployment rate for skilled workers goes up when the minimum wage rises, as it is shown in the next equation

$$
\frac{\mathrm{d} L_{d}}{\mathrm{~d} \bar{W}}=\frac{2}{\bar{W}}\left\{\frac{L_{x}}{\beta(b-1)}+\frac{\left(2-\beta_{y}\right) L_{y}}{\beta_{y}\left(b_{y}-1\right)}\right\}>0 .
$$

The effect on demand for unskilled workers is equally negative. Three important features should be highlighted. First, lower demand for unskilled workers in the export and import sectors does not have a clear relation with respect to the turnover-cost in the skilled labour market, $(b-1)$ and $\left(b_{y}-1\right)$. Second, a negative effect for unskilled workers in the import and un-tradable sectors increases as the elasticity of labour mobility increases $(\lambda)$. Third, these results are increasing as the sharing of skilled labour demands in the economy is lower, that are related to $\beta$ and $\beta_{y}$. These results are shown in Equations (24)-(26).

$$
\frac{\mathrm{d} L_{u x}}{\mathrm{~d} \bar{W}}=\frac{1}{\bar{W}} \cdot \frac{(b+1-4 \beta) L_{u x}}{\beta(b-1)}<0 \text { if and only if } b+1<4 \beta,
$$

$$
\begin{aligned}
\frac{\mathrm{d} L_{u y}}{\mathrm{~d} \bar{W}}= & -\frac{1}{\bar{W}}\left[\frac{2(b+1-2 \beta)}{\beta(b-1)} L_{u x}+\lambda\left(\frac{\bar{W}}{f^{\prime}\left(L_{n}\right)}\right)^{\lambda} L_{n}\right. \\
& \left.+\frac{b_{y}+3-2 \beta_{y}}{\left(b_{y}-1\right)} L_{u y}\right]<0, \\
\frac{\mathrm{d} L_{n}}{\mathrm{~d} \bar{W}}= & \frac{1}{\Theta \bar{W}}\left[\frac{b+1}{\beta(b-1)} L_{u x}+\lambda\left(\frac{\bar{W}}{f^{\prime}\left(L_{n}\right)}\right)^{\lambda} L_{n}\right. \\
& \left.+\frac{b_{y}+3-2 \beta_{y}}{\left(b_{y}-1\right)} L_{u y}\right]<0 .
\end{aligned}
$$

Consequently, a minimum wage exacerbates the unemployment rate for unskilled workers, as shown in Equation (27). This result is bigger as the elasticity of 
unskilled labour mobility increases.

$$
\begin{gathered}
\frac{\mathrm{d} L_{u d}}{\mathrm{~d} \bar{W}}=\frac{\Theta-1}{\Theta} \cdot \frac{1}{\bar{W}}\left[\frac{b+1}{\beta(b-1)} L_{u x}+\lambda\left(\frac{\bar{W}}{f^{\prime}\left(L_{n}\right)}\right)^{\lambda} L_{n}\right. \\
\left.+\frac{b_{y}+3-2 \beta_{y}}{\left(b_{y}-1\right)} L_{u y}\right]>0, \\
\text { being } \frac{\Theta-1}{\Theta}>0 .
\end{gathered}
$$

\subsection{Augmenting Export Sector Productivity}

Negative effects produced by increasing foreign competition in the import sector could be overcome if international trade could boost export sector productivity, especially for skilled workers. This positive result is reached simply by finding more efficient ways to use the existing skilled workers and other resources not considered in this model. As further stated analytically, output level is associated with efficiency rather than an accumulation factor.

$$
\frac{\mathrm{d} L_{x}}{\mathrm{~d} h}=\frac{(2-\beta) L_{x}}{\beta(b-1)(1+h)}>0 ; \text { and } \frac{\mathrm{d} L_{y}}{\mathrm{~d} h}=0 .
$$

Opening the economy to international trade exposes producers to greater competition, forcing them to cut cost and increase their efficiency while obtaining greater access to more and better inputs. International trade helps to reallocate resources in favour of more productive uses, as in the export sector. In the extreme case, Equation (1), where higher productivity $(h)$ is located only in the export sector, the demand for skilled workers in this sector goes up — see Equation (28) —while the demand for this type of worker in the import sector does not change, since this sector in this model does not have any relation to the spill-over positive effects, in terms of productivity $^{8}$. In this sense the skilled labour unemployment rate in the overall economy falls, as shown in Equation (29).

$$
\frac{\mathrm{d} L_{d}}{\mathrm{~d} h}=-\frac{(2-\beta) L_{x}}{\beta(b-1)(1+h)}<0,
$$

At the same time, higher productivity would probably benefit both formal and informal firms. In addition, it could provide incentives for formalization of some informal firms 9 , as shown by positive relations among

\footnotetext{
${ }^{8}$ Davidson and Matusz [9] find a strong negative correlation between net exports and job destruction using data for both the Canadian and US economies.

${ }^{9}$ Golberg and Pavnik [13] find weak evidence for a relation between trade liberalisation and informal employment in Colombia and Brazil. Their model implies that trade liberalisation leads to an increase in informal employment.
}

unskilled workers in the export sector and increasing productivity. Mathematically there is a positive relation between unskilled workers and productivity; Equation 30 .

$$
\frac{\mathrm{d} L_{u x}}{\mathrm{~d} h}=\frac{(b+1-\beta) L_{u x}}{\beta(b-1)(1+h)}>0, \text { and } \frac{\mathrm{d} L_{u y}}{\mathrm{~d} h}=0 .
$$

The result in Equation (31) shows a rise in the untradable sector, explained by better economic conditions and a decrease in unemployment for unskilled workers Equation (32). In general, firms that operate in the untradable sector could try to reduce their labour costs by replacing permanent workers with part-time labour in order to adjust the higher demand for unskilled workers by the export sector.

$$
\begin{gathered}
\frac{\mathrm{d} L_{n}}{\mathrm{~d} h}=-\frac{1}{\Theta} \cdot \frac{(b+1-\beta) L_{u x}}{\beta(b-1)(1+h)}>0, \\
\frac{\mathrm{d} L_{u d}}{\mathrm{~d} h}=-\frac{(\Theta-1)}{\Theta} \cdot \frac{(b+1-\beta) L_{u x}}{\beta(b-1)(1+h)}<0 .
\end{gathered}
$$

\section{Conclusions}

The model in this paper analytically links the main labour market issues that empirical research has observed for LDCs. These distinctive features are: The imperfect labour mobility for both skilled and unskilled workers; the labour market distortions in relation to institutional restrictions, such as minimum wage fixed by the government; and the existence of an informal sector.

The results obtained are consistent with stories about how an LDC's exposure to international trade creates opportunities for some firms, especially in the export sector, while simultaneously contributing to the downfall of other firms in the import sector. In essence, protection of trade shelters inefficient firms. There is evidence that exposing an economy to trade forces causes the less productive firms to exit the market.

International trade works as a catalyst to boost productivity in the economy, especially in the export sector. Empirical analysis of permanent trade liberalisation, like that reported by Dutt et al. [15], shows an immediate rise in unemployment, but that result tends to be reversed in the long term. However, a policy increasing the minimum wage minimises such favourable outcomes. With an increase in the minimum wage, capacity to compete in international markets falls, and therefore the overall unemployment rate rises as the labour demand in the untradable sector falls.

\section{REFERENCES}

[1] D. Davis, "Does European Unemployment Prop up American Wages? National Labor Markets and Global 
Trade," The American Economic Review, Vol. 88, No. 3, 1998, pp. 478-494. doi:10.1016/j.iref.2005.12.004

[2] J. E. Stiglitz, "Alternative Theories of Wage Determination and Unemployment in LDC's: The Labor Turnover Model," The Quarterly Journal of Economics, Vol. 88, No. 2, 1974, pp. 194-227. doi:10.2307/1883069

[3] G. S. Fields, "Segmented Labor Market Models in Developing Countries," In: H. Kincaid and D. Ross, Eds., The Oxford Handbook of the Philosophy of Economics, Oxford University Press, Oxford, 2009, pp. 476-510. doi:10.1093/oxfordhb/9780195189254.003.0018

[4] F. R. Casas, "Imperfect Factor Mobility: A Generalization and Synthesis of Two-Sector Models of International Trade," The Canadian Journal of Economics, Vol. 17, No. 4, 1984, pp. 747-761. doi:10.2307/135070

[5] A. K. Parai and H. Beladi, "Labor Movility and Unemployment," Southern Economic Journal, Vol. 64, No. 1, 1997, pp. 180-190. doi:10.2307/1061046

[6] G. Wei and Y. Shigemi, "Imperfect Labor Mobility and Unemployment in a Dual Economy," Review of International Economics, Vol. 34, No. 4, 2006, pp. 698-708. doi:10.1111/j.1467-9396.2006.00650.x

[7] S. Marjit, "Economic Reform and Informal Wage-A General Equilibrium Analysis," Journal of Development Economics, Vol. 72, No. 1, 2003, pp. 371-378. doi:10.1016/S0304-3878(03)00082-8

[8] S. Chaudhuri and Y. Shigemi, "Economic Liberalization and Wage Inequality in the Presence of Labour Market Imperfection," International Review of Economics and Finance, Vol. 16, No. 4, 2007, pp. 592-603. doi:10.1016/j.iref.2005.12.004

[9] C. Davidson and S. Matusz, "Trade and Turnover: Theory and Evidence," Review of International Economics, Vol. 13, No. 5, 2005, pp. 861-880. doi:10.1111/j.1467-9396.2005.00541.x

[10] P. Fajnzylber and W. Maloney, "Labor Demand and Trade Reform in Latin America," Journal of International Economic, Vol. 66, No. 2, 2005, pp. 423-446. doi:10.1016/j.jinteco.2004.08.002

[11] P. Goldberg and N. Pavcnik, "Trade, Wages, and the Political of Trade Protection: Evidence from Colombian Trade Reforms," Journal of international Economics, Vol. 66, No. 1, pp. 2005, pp. 75-105. doi:10.1016/i.jinteco.2004.04.005

[12] M. Bosh, E. Goni and W. Maloney, "The Deteminants of Rising Informality in Brazil: Evidence from Gross Worker Flows," World Bank Discussion Paper No. 4375, 2007.

[13] P. Goldberg and N. Pavcnik, "The Response of the Informal Sector to Trade Liberalization," Journal of Development Economics, Vol. 72, No. 2, 2003, pp. 463-496. doi:10.1016/S0304-3878(03)00116-0

[14] G. Esquivel and J. A. Rodríguez-López, "Technology, Trade, and Wage Inequality in Mexico before and after NAFTA," Journal of Development Economics, Vol. 72, No. 2, 2003, pp. 543-565. doi:10.1016/S0304-3878(03)00119-6

[15] P. D. Dutt Mitra and P. Ranjan, "International Trade and Unemployment: Theory and Cross-National Evidence," Journal of International Economic, Vol. 78, No. 1, 2009, pp. 32-44. doi:10.1016/i.jinteco.2009.02.005 


\section{Appendix 1}

\section{First-Order Necessary Conditions:}

$$
\begin{gathered}
\frac{\partial \pi_{x}}{\partial L_{x}}=\frac{\beta}{(1+S)}\left(\frac{L_{u x}}{L_{x}}\right)^{1-\beta}-r \frac{1+\alpha\left(1+S_{y}\right)}{1+h}-\frac{\bar{W}^{2} b}{r} L_{x}^{b-1}=0 . \\
\frac{\partial \pi_{x}}{\partial L_{u x}}=\frac{(1-\beta)}{(1+S)}\left(\frac{L_{x}}{L_{u x}}\right)^{\beta}-\frac{\bar{W}\left(1+\alpha\left(1+S_{y}\right)\right)}{1+h}=0 . \\
\frac{\partial \pi_{x}}{\partial r}=-\frac{1+\alpha\left(1+S_{y}\right)}{1+h} L_{x}+\left(\frac{\bar{W}}{r}\right)^{2} L_{x}^{b}=0 . \\
\frac{\partial \pi_{y}}{\partial L_{y}}=\left(1+S_{y}\right) \beta_{y}\left(\frac{L_{u y}}{L_{y}}\right)^{1-\beta_{y}}-r_{y}-\frac{\bar{W}^{2} b_{y}}{r_{y}} L_{y}^{b_{y}-1}=0 . \\
\frac{\partial \pi_{y}}{\partial L_{u y}}=\left(1+S_{y}\right)\left(1-\beta_{y}\right)\left(\frac{L_{y}}{L_{u y}}\right)^{\beta_{y}}-\bar{W}=0 . \\
\frac{\partial \pi_{y}}{\partial r_{y}}=-L_{y}+\left(\frac{\bar{W}}{r_{y}}\right)^{2} L_{y}^{b_{y}}=0 . \\
\frac{\partial \pi_{n}}{\partial L_{n}}=f^{\prime}\left(L_{n}\right)-W_{n}=0 ; \text { where } f^{\prime \prime}\left(L_{n}\right)<0 .
\end{gathered}
$$

Substituting (35) into (33), and (38) into (36), the first-order conditions can be rewritten as

$$
\begin{gathered}
\frac{\beta}{1+S}\left(\frac{L_{u x}}{L_{x}}\right)^{1-\beta}-(1+b) \bar{W}\left(\frac{1+\alpha\left(1+S_{y}\right)}{1+h}\right)^{\frac{1}{2}} \frac{b-1}{L_{x}^{2}}=0 . \\
\frac{1-\beta}{1+S}\left(\frac{L_{x}}{L_{u x}}\right)^{\beta}-\frac{\bar{W}\left(1+\alpha\left(1+S_{y}\right)\right)}{1+h}=0 . \\
\left(1+S_{y}\right) \beta_{y}\left(\frac{L_{u y}}{L_{y}}\right)^{1-\beta_{y}}-\bar{W}\left(1+b_{y}\right) L_{y}^{\frac{b_{y}-1}{2}}=0 . \\
\left(1+S_{y}\right)\left(1-\beta_{y}\right)\left(\frac{L_{y}}{L_{u y}}\right)^{\beta_{y}}-\bar{W}=0 . \\
f^{\prime}\left(L_{n}\right)=W_{n} .
\end{gathered}
$$

\section{Appendix 2}

\section{Comparative-Static Aspects}

The first-order conditions, Equations (40)-(43), are differentiated. After that, Equations (4)-(6) and (44) are used, as the first-order conditions again. Thus, the following differentiated equation system is obtained:

$$
-\frac{b-2 \beta+1}{2} \frac{\mathrm{d} L_{x}}{L_{x}}+\frac{(1-\beta) \mathrm{d} L_{u x}}{L_{u x}}=\frac{\mathrm{d} S}{1+S}+\frac{\alpha \mathrm{d} S_{y}}{2\left(1+\alpha\left(1+S_{y}\right)\right)}+\frac{\mathrm{d} \bar{W}}{\bar{W}}-\frac{\mathrm{d} h}{2(1+h)} .
$$




$$
\frac{\mathrm{d} L_{x}}{L_{x}}-\frac{\mathrm{d} L_{u x}}{L_{u x}}=\frac{\mathrm{d} S}{\beta(1+S)}+\frac{\alpha \mathrm{d} S_{y}}{\beta\left(1+\alpha\left(1+S_{y}\right)\right)}+\frac{\mathrm{d} \bar{W}}{\beta \bar{W}}-\frac{\mathrm{d} h}{\beta(1+h)} .
$$

taking into account that $L_{y}=-\left(L_{X}+L_{d}\right)$, and from Equation (6) $L_{u y}=\left(\frac{\bar{W}}{f^{\prime}\left(L_{n}\right)}\right)^{\lambda} L_{n}-L_{u x}$, we have

$$
\begin{gathered}
\frac{1-2 \beta_{y}+b_{y}}{2\left(1-\beta_{y}\right)} \cdot \frac{\mathrm{d} L_{x}+\mathrm{d} L_{d}}{L_{y}}-\frac{\Theta \mathrm{d} L_{n}+\mathrm{d} L_{u x}}{L_{u y}}=-\frac{\mathrm{d} S_{y}}{\left(1+S_{y}\right)\left(1-\beta_{y}\right)}-\left(\lambda\left(\frac{\bar{W}}{f^{\prime}\left(L_{n}\right)}\right)^{\lambda} L_{n}-\frac{L_{u y}}{\left(1-\beta_{y}\right)}\right) \frac{\mathrm{d} \bar{W}}{\bar{W} L_{u y}} . \\
-\frac{\mathrm{d} L_{x}+\mathrm{d} L_{d}}{L_{y}}+\frac{1}{L_{u y}}\left(\Theta \mathrm{d} L_{n}+\mathrm{d} L_{u x}\right)=-\frac{\mathrm{d} S_{y}}{\beta_{y}\left(1+S_{y}\right)}+\left(\lambda\left(\frac{\bar{W}}{f^{\prime}\left(L_{n}\right)}\right)^{\lambda} L_{n}-L_{u y}\right) \frac{\mathrm{d} \bar{W}}{\bar{W} L_{u y}}
\end{gathered}
$$

and the parameter $\Theta$ is defined as

$$
\Theta=\left(\frac{\bar{W}}{f^{\prime}\left(L_{n}\right)}\right)^{\lambda}\left[\lambda \frac{f^{\prime \prime}\left(L_{n}\right)}{f^{\prime}\left(L_{n}\right)} L_{n}-1\right]<-1 .
$$

\section{The previous four equations are written in matrix form as}

$$
H \cdot \mathrm{d} L=A \cdot \mathrm{d} D,
$$

where

$$
H=\left(\begin{array}{cccc}
-\frac{b-2 \beta+1}{2 L_{x}} & \frac{(1-\beta)}{L_{u x}} & 0 & 0 \\
\frac{1}{L_{x}} & -\frac{1}{L_{u x}} & 0 & 0 \\
\frac{1-2 \beta_{y}+b_{y}}{2\left(1-\beta_{y}\right) L_{y}} & -\frac{1}{L_{u y}} & \frac{1-2 \beta_{y}+b_{y}}{2\left(1-\beta_{y}\right) L_{y}} & -\frac{1}{L_{u y}} \Theta \\
-\frac{1}{L_{y}} & \frac{1}{L_{u y}} & -\frac{1}{L_{y}} & \frac{1}{L_{u y}} \Theta
\end{array}\right),
$$

and

$$
A=\left(\begin{array}{cccc}
\frac{1}{(1+S)} & \frac{1}{\bar{W}} & -\frac{1}{2} \frac{1}{(1+h)} & +\frac{1}{2} \frac{\alpha}{\left[\left(1+\alpha\left(1+S_{y}\right)\right)\right]} \\
\frac{1}{\beta(1+S)} & \frac{1}{\bar{W} \beta} & -\frac{1}{(1+h) \beta} & \frac{\alpha}{\left[1+\alpha\left(1+S_{y}\right)\right] \beta} \\
0 & -\left[\lambda\left(\frac{\bar{W}}{f^{\prime \prime}}\right)^{\lambda} L_{n}-\frac{L_{u y}}{\left(1-\beta_{y}\right)}\right] \frac{1}{\bar{W} L_{u y}} & 0 & -\frac{1}{\left(1-\beta_{y}\right)\left(1+S_{y}\right)} \\
0 & {\left[\lambda\left(\frac{\bar{W}}{f^{\prime \prime}}\right)^{\lambda} L_{n}+L_{u y}\right] \frac{1}{W L_{u y}}} & 0 & -\frac{1}{\left(1+S_{y}\right) \beta_{y}}
\end{array}\right),
$$

being $\boldsymbol{D} \boldsymbol{L}^{\prime}=\left(\begin{array}{llll}\mathrm{d} L_{x} & \mathrm{~d} L_{u x} & \mathrm{~d} L_{d} & \mathrm{~d} L_{n}\end{array}\right)$ and $\mathrm{d} \boldsymbol{D}^{\prime}=\left(\begin{array}{llll}\mathrm{d} S & \mathrm{~d} S_{y} & \mathrm{~d} W & \mathrm{~d} h\end{array}\right)$.

The inverse matrix of $H$, denoted by $H^{-1}$, is 


$$
H^{-1}=\left(\begin{array}{cccc}
-\frac{2 L_{x}}{(b-1)} & -\frac{2(1-\beta) L_{x}}{(b-1)} & 0 & 0 \\
-\frac{2 L_{u x}}{(b-1)} & \frac{(b-2 \beta+1) L_{u x}}{(b-1)} & 0 & 0 \\
\frac{2 L_{x}}{(b-1)} & \frac{2(1-\beta) L_{x}}{(b-1)} & \frac{2\left(1-\beta_{y}\right) L_{y}}{\left(b_{y}-1\right)} & \frac{2\left(1-\beta_{y}\right) L_{y}}{\left(b_{y}-1\right)} \\
\frac{2 L_{u x}}{\Theta(b-1)} & \frac{(b-2 \beta+1) L_{u x}}{\Theta(b-1)} & \frac{2\left(1-\beta_{y}\right) L_{u y}}{\Theta\left(b_{y}-1\right)} & \frac{\left(b_{y}-2 \beta_{y}+1\right) L_{u y}}{\Theta\left(b_{y}-1\right)}
\end{array}\right)
$$

